\title{
Patient expectations, outcomes and satisfaction: related, relevant or redundant?
}

\author{
Authors Paul Licina ${ }^{1,2}$, Michelle Johnston ${ }^{1,2}$, Laura Ewing ${ }^{1}$, Mark Pearcy ${ }^{1}$ \\ Institutions ${ }^{1}$ Institute of Health and Biomedical Innovation, Queensland University of Technology, \\ Brisbane, Australia \\ ${ }^{2}$ Brisbane Private Research Group, Brisbane Private Hospital, Brisbane, Queensland, Australia
}

\begin{tabular}{l|l|}
\hline Final class of \\
evidence-treatment \\
Study design \\
\hline RCT \\
Cohort \\
Case control \\
\hline Case series \\
\hline Methods \\
\hline Concealed allocation (RCT) \\
\hline Intention to treat (RCT) \\
\hline Blinded/independent \\
evaluation of primary outcome & \\
\hline F/U $\geq 85 \%$ & \\
\hline Adequate sample size & \\
\hline Control for confounding & \\
\hline Overall class of evidence & IV \\
\hline
\end{tabular}

\section{ABSTRACT}

Study design: A prospective case series of patients undergoing lumbar spine surgery.

Objective: Is there a correlation between patients' expectations before lumbar surgery, postoperative outcomes, and satisfaction levels?

Methods: A prospective study of 145 patients undergoing primary, single-level surgery for degenerative lumbar conditions was conducted. Oswestry Disability Index, back Visual Analog Scale (VAS), and leg VAS were assessed preoperatively and at 6 weeks and 6 months after surgery. Patients' expectations were measured preoperatively by asking them to score the level of pain and disability that would be least acceptable for them to undergo surgery and be satisfied. Satisfaction was assessed 6 weeks postoperatively with a Likert scale. Differences in patient expectations between actual and expected improvements were quantified.

Results: Most patients had a clinically relevant improvement, but only about half achieved their expectations. Satisfaction did not correlate with preoperative pain or disability, or with patient expectation of improvement. Instead, satisfaction correlated with positive outcomes.

Conclusions: Patient expectations have little bearing on final outcome and satisfaction. 


\section{STUDY RATIONALE AND CONTEXT}

The relationship between patient expectations and satisfaction, and their influence on outcome, is complex, and opinion varies. Some suggest higher expectations predict greater satisfaction [1-3] and better outcome [4, 5], or that greater satisfaction is associated with better outcome [6]. Others have found some patients were dissatisfied even if expectations were met [7], or that functional outcome is a weak correlate of satisfaction [8].

\section{CLINICAL QUESTION}

What do patients expect from their surgical treatment, and are they satisfied with their postoperative results? What are the relationships between expectations, outcome, and satisfaction?

Fig 1

Patient sampling and selection.

Total patients receiving intervention during time period $(\mathrm{N}=\mathbf{2 5 6})$
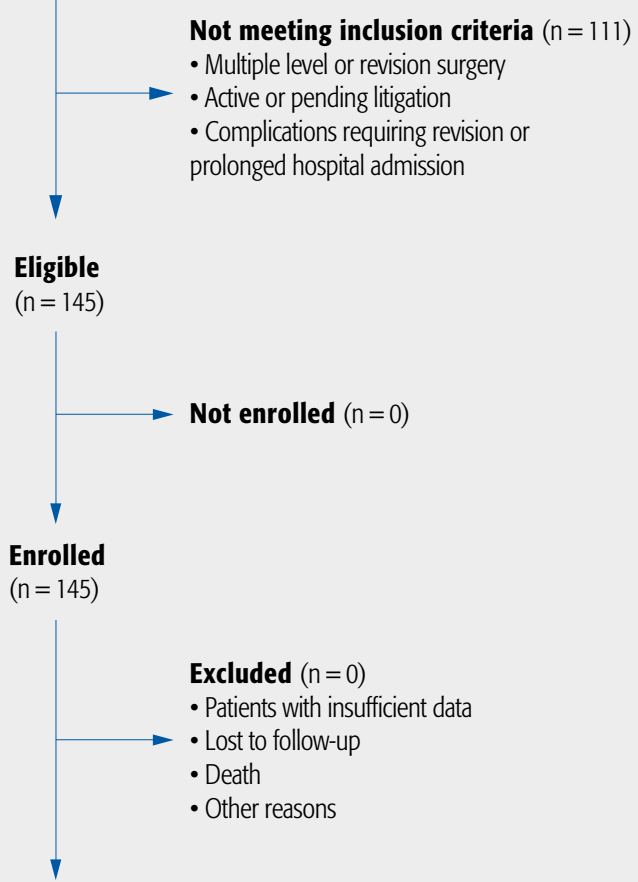

Patients available for analysis $(n=145)$

\section{METHODS}

Study design: Prospective case series study.

Inclusion criteria: Primary, single-level surgery for degenerative lumbar spine conditions from June 2007 to February 2009 by a single surgeon (PL); complete data.

\section{Exclusion criteria (Fig 1)}

- Multiple level or revision surgery or incomplete data

- Surgical complications requiring revision or prolonged hospital admission

- Patients with active or pending litigation

\section{Patient population and selection (Fig 1):}

- Patients undergoing primary, single-level surgery by a single surgeon for degenerative lumbar conditions were included.

- The diagnoses included disc prolapse; isthmic and degenerative spondylolisthesis; central, lateral recess, and foraminal spinal stenosis; and discogenic low back pain. Duration of symptoms ranged from 6 weeks (disc prolapse) to 6 months (stenosis, spondylolisthesis, and back pain).

- Routine preoperative counseling by surgeon and clinical staff was conducted on at least two occasions for each patient. This included risks, benefits, potential complications, and goals of surgery. Mutual patient and surgeon expectations were documented preoperatively.

\section{Outcomes and factors to be evaluated:}

- Oswestry Disability Index (ODI), back Visual Analog Scale (VAS), and leg VAS scores were collected preoperatively, and at 6 weeks and 6 months postoperatively.

- Patients' expectations were measured preoperatively by asking them to score the level of pain (back and leg VAS) and disability (ODI) that would be least acceptable for them to undergo surgery and be satisfied with the outcome.

- Satisfaction was assessed 6 weeks postoperatively with a 5 -point Likert-type scale.

- The data were collected by a research assistant. This was at the conclusion of the normal preoperative counseling to standardize this process and to minimize potential bias in patient scores, in particular the satisfaction levels.

\section{Analysis:}

- Actual improvements in back and leg VAS and ODI were calculated by subtracting the postoperative score from the preoperative score. 
- The accepted minimal clinically important difference (MCID) of 12.8 in ODI, 1.2 in back VAS, and 1.6 in leg VAS [9] was compared with the actual improvement to determine whether these improvements were clinically relevant.

- To determine whether the expected improvement had been met, the difference between actual (6-month postoperative) improvement and expected improvement was calculated $(\triangle \mathrm{AB})$. A negative value meant that the expectation had not been met and a value of zero or greater meant that the expectation had been met or exceeded.

- However, to determine whether this difference was clinically relevant, the accepted MCID was applied to the value, and this was termed the clinically relevant benefit difference $(\Delta R B)$. The reason for the application of this margin was to recognize that a small negative value of $\triangle \mathrm{AB}$ may be of no clinical relevance.
Table 1 Patient characteristics and surgical procedures.*

\begin{tabular}{ll}
\hline & $\mathrm{N}=145$ \\
\hline $\begin{array}{l}\text { Patient characteristics, No. (\%) } \\
\text { Age, } \mathrm{y} \text { (mean } \pm \text { SD) }\end{array}$ & $54 \pm 15$ \\
\hline Male & $91(63)$ \\
\hline Privately insured & $117(81)$ \\
\hline Workers compensation & $22(15)$ \\
\hline Uninsured & $6(4)$ \\
\hline $\begin{array}{l}\text { Surgical procedures, No. (\%) } \\
\text { Discectomy }\end{array}$ & $58(40)$ \\
\hline Laminectomy & $20(14)$ \\
\hline Laminectomy and posterolateral fusion & $27(19)$ \\
\hline TLIF & $27(19)$ \\
\hline ALIF & $13(9)$ \\
\hline
\end{tabular}

* TLIF indicates transforaminal lumbar interbody fusion; ALIF, anterior lumbar interbody fusion.

\section{RESULTS}

- Hundred and forty-five patients were studied. Patient characteristics and surgical procedures are outlined in Table 1.

- Most patients improved with surgery. Absolute and clinically important changes in ODI, back VAS and leg VAS at 6 weeks and 6 months are shown in Table 2.

- The average preoperative scores decreased at 6 weeks and 6 months, but not to the average expected levels (Table 3).

- Expectations were met or exceeded in more than half of cases. Most were very satisfied with the outcome. Ninety percent of patients expected an ODI $\leq 20,95 \%$ expected leg VAS $\leq 2$, and $80 \%$ expected back VAS $\leq 2$. Interestingly, some patients expected to do poorly (Fig 2).

- The numbers of patients who met or exceeded their expectations are shown in Table 4. The percentages increased from 6 weeks to 6 months and the percentages were higher when the MCID margin was applied to account for those patients with small gaps between expectations and outcomes (Fig 3). Most patients (109/145) were "very satisfied" and another 26 patients reported being "satisfied" with their outcome. The least satisfied were the ten "somewhat satisfied" patients. The "somewhat satisfied" patients had higher scores of disability and back pain postoperatively compared with the whole cohort. Additionally, they expected more pain after surgery (Table 5).

- Analysis of the correlation between expectation and satisfaction was difficult. We examined the "very satisfied" patients, as numbers for the "satisfied" and "somewhat satisfied" groups were too small for analysis. We found no correlation as to whether they had a high or low expected change in their scores (Table 6).

- Further detailed investigation of those who either achieved their expectations by a high level or by a low level (expected to final), similarly, found no correlation. There was no statistically significant relationship observed between the expected ODI and VAS changes in the "very satisfied" patients with high and low preoperative expectations and their satisfaction rates (Table 7).

Table 2 Change in ODI and VAS at 6 weeks and 6 months after surgery.*

\begin{tabular}{|c|c|c|c|c|c|c|c|c|}
\hline & \multicolumn{2}{|c|}{$\begin{array}{l}\text { Improved from } \\
\text { baseline, No. (\%) }\end{array}$} & \multicolumn{2}{|c|}{$\begin{array}{l}\text { Achieved clinical benefit, } \\
\text { No. }(\%)\end{array}$} & \multicolumn{2}{|c|}{$\begin{array}{l}\text { No improvement from } \\
\text { baseline, No. (\%) }\end{array}$} & \multicolumn{2}{|c|}{$\begin{array}{l}\text { Worse compared with } \\
\text { baseline, No. (\%) }\end{array}$} \\
\hline & $6 \mathrm{wk}$ & $6 \mathrm{mo}$ & $6 \mathrm{wk}$ & $6 \mathrm{mo}$ & 6 wk & $6 \mathrm{mo}$ & 6 wk & $6 \mathrm{mo}$ \\
\hline ODI & $138(95)$ & $138(95)$ & $95(66)$ & $111(77)$ & $2(1)$ & $4(3)$ & $5(3)$ & $3(2)$ \\
\hline Back VAS & $130(90)$ & $133(92)$ & $105(72)$ & $110(76)$ & $7(5)$ & $6(4)$ & $8(6)$ & $6(4)$ \\
\hline Leg VAS & $131(90)$ & $130(90)$ & 119 (82) & $124(86)$ & $8(6)$ & $9(6)$ & $6(4)$ & $6(4)$ \\
\hline
\end{tabular}

* ODI indicates Oswestry Disability Index; VAS, Visual Analog Scale. 
Fig 2 Patients' expected outcome scores recorded preoperatively. Numbers of patients in bands of expected values are shown to indicate the nature of the expectations. ODI indicates Oswestry Disability Index; VAS, Visual Analog Scale.
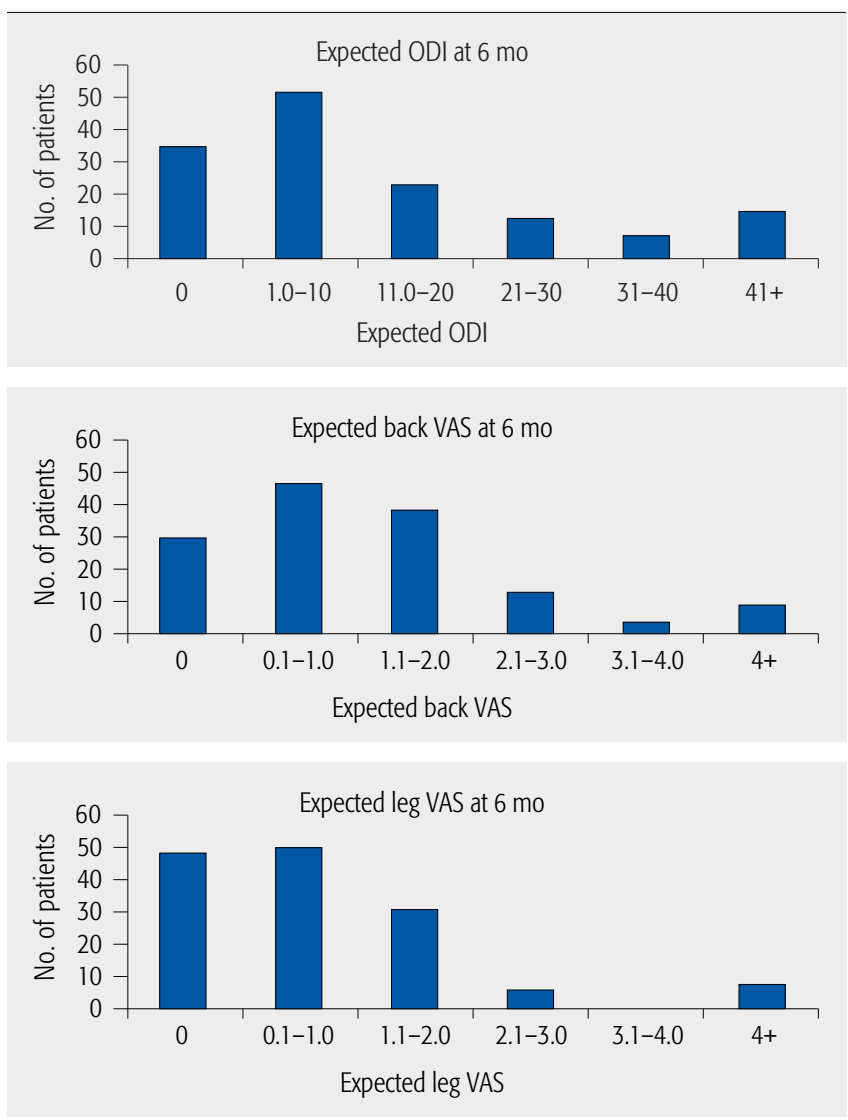

Fig 3 Patients meeting or exceeding expectations (Oswestry Disability Index [ODI] and Visual Analog Scale [VAS] scores) at 6 months.

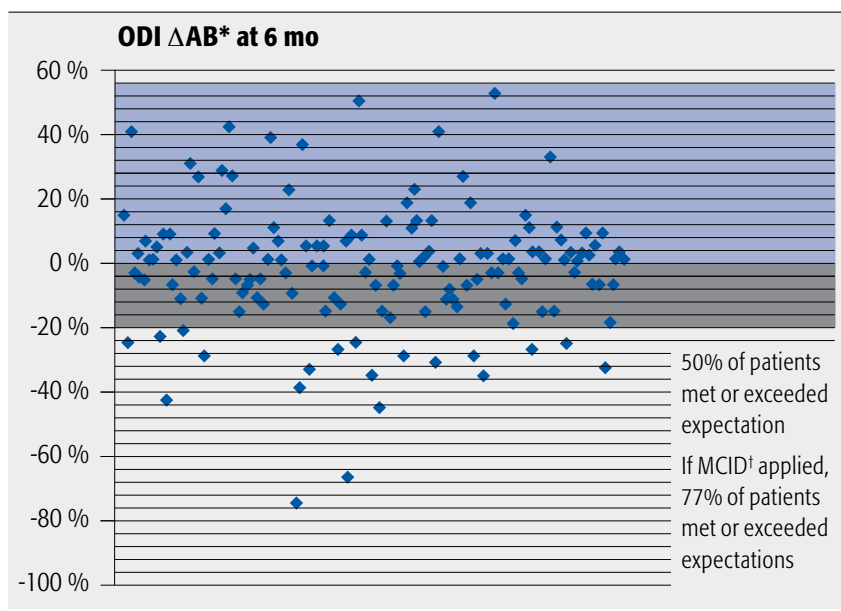

$* \triangle \mathrm{AB}$ is the difference between expected improvement and actual improvement.

${ }^{\dagger} \mathrm{MCID}$ is the minimal clinically important difference (which for ODI is 12.8).

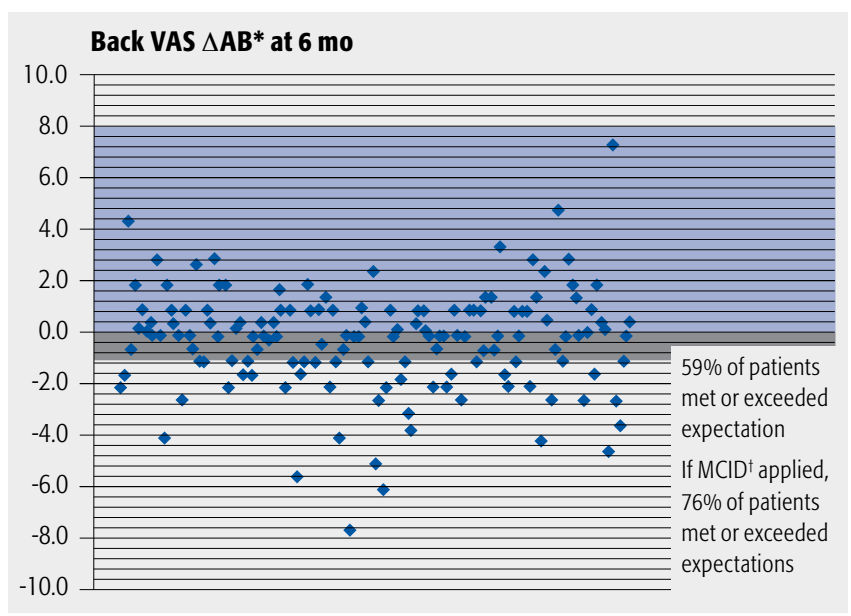

* $\triangle \mathrm{AB}$ is the difference between expected improvement and actual improvement.

${ }^{\dagger} \mathrm{MCID}$ is the minimal clinically important difference (which for back VAS is 1.2)

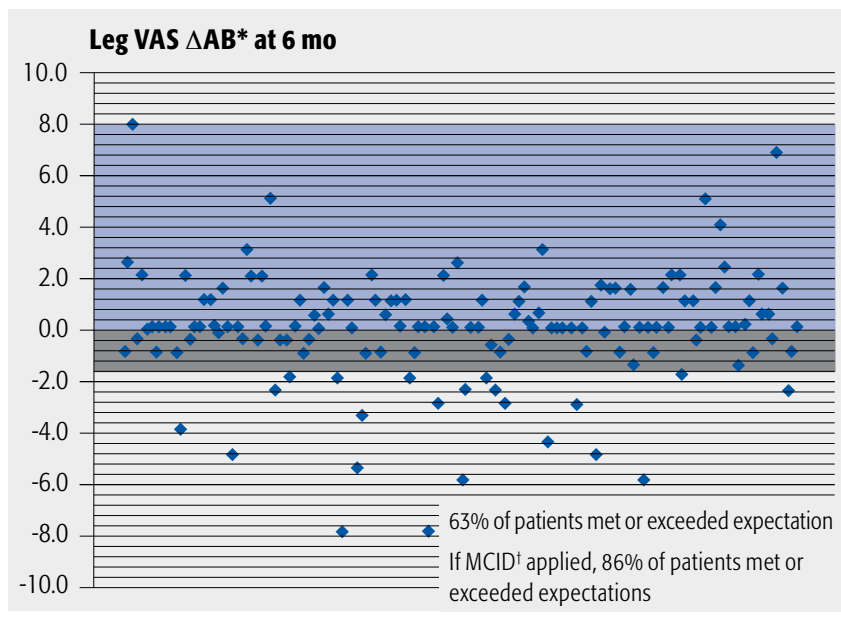

* $\triangle A B$ is the difference between expected improvement and actual improvement.

$\dagger$ MCID is the minimal clinically important difference (which for back VAS is 1.6). 
Table 3 Average outcome and expectation scores of patients.*

\begin{tabular}{lllll}
\hline & Preop & $\mathbf{6}$ wk & $\mathbf{6}$ mo & $\begin{array}{l}\text { Expecta- } \\
\text { tion }\end{array}$ \\
\hline ODI & $51 \%$ & $22 \%$ & $17 \%$ & $14 \%$ \\
\hline Back VAS & 5.8 & 2.1 & 1.7 & 1.5 \\
\hline Leg VAS & 6.2 & 1.4 & 1.2 & 1.1 \\
\hline
\end{tabular}

* Preop indicates preoperative; ODI, Oswestry Disability Index; and VAS, Visual Analog Scale.

Table 4 Percentage of patients who achieved actual $(\triangle A B)$ and clinically relevant expectations $(\Delta \mathrm{RB})$.* $^{*}$

\begin{tabular}{lllll}
\hline & $\mathbf{6} \mathbf{w k}, \mathbf{\%}$ & $\mathbf{6} \mathbf{~ m o}, \mathbf{\%}$ \\
\hline ODI & $\boldsymbol{\Delta} \mathbf{A B}$ & $\Delta \mathbf{R B}$ & $\Delta \mathbf{A B}$ & $\Delta \mathbf{R B}$ \\
\hline Back VAS & 57 & 66 & 50 & 77 \\
\hline Leg VAS & 62 & 72 & 59 & 76 \\
\hline
\end{tabular}

* ODI indicates Oswestry Disability Index; VAS, Visual Analog Scale.
Table 5 Outcome and expectations of "somewhat satisfied" patients compared with "very satisfied" and "satisfied" patients $(P<.05$ shaded).*

\begin{tabular}{|c|c|c|c|c|}
\hline & Preoperative & $6 \mathrm{wk}$ & $6 \mathrm{mo}$ & Expectation \\
\hline \multicolumn{5}{|l|}{ ODI scores } \\
\hline Somewhat $(n=10)$ & $63 \%$ & $50 \%$ & $38 \%$ & $17 \%$ \\
\hline $\begin{array}{l}\text { Very satisfied and } \\
\text { satisfied }(n=135)\end{array}$ & $50 \%$ & $20 \%$ & $16 \%$ & $14 \%$ \\
\hline \multicolumn{5}{|l|}{ Back VAS scores } \\
\hline Somewhat $(n=10)$ & 6.5 & 5.9 & 4.3 & 2.6 \\
\hline $\begin{array}{l}\text { Very satisfied and } \\
\text { satisfied }(n=135)\end{array}$ & 5.8 & 1.8 & 1.5 & 1.4 \\
\hline \multicolumn{5}{|l|}{ Leg VAS scores } \\
\hline Somewhat $(n=10)$ & 6.1 & 2.9 & 3 & 2 \\
\hline $\begin{array}{l}\text { Very satisfied and } \\
\text { satisfied }(n=135)\end{array}$ & 6.2 & 1.3 & 1.1 & 1.1 \\
\hline
\end{tabular}

* ODI indicates Oswestry Disability Index; VAS, Visual Analog Scale.

Table 6 Comparison of "very satisfied" patient expectations (preoperative ODI or VAS score - expected ODI or VAS score) and satisfaction rates $(P>.05$ for all groups).*

\begin{tabular}{lllllll}
\hline Preoperative to & \multicolumn{5}{c}{ Expected change } \\
\cline { 2 - 7 } expected change & Very high & Very low & Very high & Very low & Very high & Very low \\
& ODI & ODI & back VAS $(>8)$ & back VAS $(<2)$ & leg VAS $(>8)$ & leg VAS $(<2)$ \\
\hline Very satisfied & $(>60)$ & $(<10)$ & & & & \\
\hline
\end{tabular}

* ODI indicates Oswestry Disability Index; VAS, Visual Analog Scale.

Table 7 "Very satisfied" patients and the degree expectation exceeded or not reached (total number of patients, and percentages).*

\begin{tabular}{|c|c|c|c|c|c|c|}
\hline & \multicolumn{6}{|c|}{ Difference between 6-mo postoperative ODI or VAS and expected ODI or VAS } \\
\hline & ODI & ODI & Back VAS & Back VAS & Leg VAS & Leg VAS \\
\hline & $\Delta \geq 15$ & $\Delta \leq-30$ & $\Delta \geq 2$ & $\Delta \leq-2$ & $\Delta \geq 2$ & $\Delta \leq-2$ \\
\hline "Very satisfied" & $12 / 18(67 \%)$ & $9 / 15(60 \%)$ & $5 / 9(56 \%)$ & $10 / 19(53 \%)$ & $5 / 10(50 \%)$ & $11 / 18(61 \%)$ \\
\hline
\end{tabular}

* ODI indicates Oswestry Disability Index; VAS, Visual Analog Scale. 


\section{DISCUSSION}

\section{Strengths}

- Patients had high expectations and most were satisfied regardless of whether they exceeded or did not meet their expectations. Approximately half of the patients reached their expectations. Despite this, most were satisfied with their outcome.

- Those less (somewhat) satisfied patients expected more pain and indeed had more pain postoperatively.

- No other correlation between satisfaction, expectation, and outcome was identified.

\section{Limitations}

- Measurement of satisfaction with a single 5-point scale is simplistic, and patients may score to please. Assessment from outside the practice environment may give a more independent score.

- Patients may have experienced difficulty with quantifying their expectations with this methodology.

- A more homogeneous group of patients may have yielded different results.

- Further statistical analysis of a larger cohort would be required to determine any relationship between patients' preoperative expectations and their satisfaction with the surgical outcome.

\section{Clinical relevance and impact}

- Meeting patient expectations and achieving patient satisfaction are important outcomes in any surgical environment. However, these subjective variables are difficult to evaluate and interpret objectively.

- Furthermore, their relevance to clinical practice and how to change practice to optimize them is incompletely understood [8].

- A statistically significant relationship between patients' preoperative expectations and satisfaction with surgical outcome was not observed within this study.

- Measurement of expectations may identify those with unrealistic expectations and allow them to be counseled preoperatively, but in this study there was no clear influence of outcome on satisfaction.

\section{SUMMARY AND CONCLUSIONS}

This was a study of the relationship between patient preoperative expectations and satisfaction with surgical outcome for single-level primary lumbar surgery conducted by a single surgeon. The results showed that:

- Patients had high expectations, and these were reached in approximately half of the cohort. Most patients were satisfied, and those less (somewhat) satisfied had poorer outcomes overall.

- There was no other correlation found in this study between satisfaction, expectations, and outcome.

\section{REFERENCES}

1. Wilson SJ, Saling MM, Lawrence J, et al (1999) Outcome of temporal lobectomy: expectations and the prediction of perceived success. Epilepsy Res; 36(1):1-14.

2. Wheelock I, Peterson C, Buchtel HA (1998) Presurgery expectations, postsurgery satisfaction, and psychosocial adjustment after epilepsy surgery. Epilepsia; 39(5):487-494.

3. Gepstein R, Arizon Z, Adunsky A, et al (2006) Decompression surgery for lumbar spinal stenosis in the elderly: preoperative expectations and postoperative satisfaction. Spinal Cord; 44(7):427-431.

4. Gandhi R, Davey JR, Mahomed N (2008) Patient expectations predict greater pain relief with joint arthroplasty. J Arthroplasty; 24(5):716-721.

5. Lutz GK, Butzlaff ME, Atlas SJ, et al (1999) The relation between expectations and outcomes in surgery for sciatica. J Gen Intern Med; 14(12):740-744.

6. Skolasky RL, Albert TJ, Vaccaro AR, et al (2009) Patient satisfaction in the cervical spine research society outcomes study: relationship to improved clinical outcome. Spine J; 9(3):232-239.

7. Toyone T, Tanaka T, Kato D, et al (2005) Patients' expectations and satisfaction in lumbar spine surgery. Spine; 30(23):2689-2694.

8. Yamashita K, Hayashi J, Ohzono $K$, et al (2003) Correlation of patient satisfaction with symptom severity and walking ability after surgical treatment for degenerative lumbar spinal stenosis. Spine; 28(21):2477-2481.

9. Copay AG, Glassman SD, Subach MD, et al (2008) Minimum clinically important difference in lumbar spine surgery patients: a choice of methods using the Oswestry Disability Index, Medical Outcomes Study questionnaire Short Form 36, and pain scales. Spine J; 8(6):968-974. 


\section{EDITORIAL PERSPECTIVE}

This study received high praise from our reviewers for its idea and for the study design and applied methodology. As in any study, there were some questions raised but Licina et al received unanimous praise for their effort and for adding to our current knowledge base on a complex subject to a significant degree.

Potential interrelations of surgical outcomes from a provider perspective, subjective patient outcomes, patient satisfaction, and patient expectations are incredibly important yet poorly understood. This study has taken a major step forward in this regard by looking at a prospectively gathered data set from an experienced single surgeon regarding a homogeneous group of patients presented for surgical treatment of a single-level degenerative lumbar disc disease. It is sobering to hear that in this select group of patients only 50-59\% achieved their expectations regarding low back pain relief; $76-77 \%$ attained an improvement of at least the MCID. In this era of increasing emphasis on shared decision-making, having such data available for preoperative counseling with patients seems vital as frequently difficult decisions need to be made.

As to criticisms of the study, our reviewers remarked that the study population was actually heterogeneous as low back pain oriented treatments (such as anterior lumbar interbody fusion) were mixed together with presumably radiculopathy related conditions, such as disc herniation. The age-old questionif radiculopathy is more amenable to surgical treatment than low back pain - may be raised again. Ideally, these subpopulations would be separated from one another to try to look for heterogeneous treatment effects. Other patient variables, such as body mass index, duration of symptoms, preoperative opiate use, and comorbidities were not evaluated either. Again, the current study cohort is too small to allow for such analysis.

Other factors to consider in the results reporting are that as positive as providers may interpret some of the results (such as the improvements for baseline presented in Table 2), remember that this study excluded patients with complications, revisions or patients involved in claims and litigation situations. Inclusions of such patient populations would have likely decreased the outcomes scores to some degree.

Finally, this article reinforces the importance of preoperative counseling (and documentation) of expected outcomes. Can modulations of patient satisfaction be attained through better, more in-depth or just more formally applied risk and benefit preoperative counseling sessions?

No doubt this article will serve as a thought-provoking starting point for further discussions and study on the contentious subject of elective back surgery. The EBSJ editors appreciate the authors valuable contribution. 